\title{
DINÁMICA CONTEMPORÁNEA DEL RETORNO MIGRA- TORIO: ESTUDIO DE CASO EN COMUNIDADES DEL SUR DEL ESTADO DE MÉXICO. ${ }^{1}$
}

\author{
CONTEMPORARY DINAMICS OF RETURN MIGRATION: \\ CASE STUDY FROM THE SOUTH REGION OF ESTADO DE MÉXICO. \\ DYNAMIQUES CONTEMPORAINES DE LA MIGRATION DE RETOUR: \\ ETUDE DE CAS AU REGION SUD DE L'ÉTAT DE MEXIQUE. \\ DINÂMICA CONTEMPORÂNEA DO RETORNO MIGRATÓRIO: ESTUDO \\ DE CASO NAS COMUNIDADES DO SUL DO ESTADO DO MÉXICO.
}

\section{Ana Elizabeth Jardón Hernández* \\ Norma Baca Tavira**}

RESUMEN: En los últimos años, particularmente después de la crisis económica que experimentó Estados Unidos en 2008, se despertó un genuino interés por estudiar desde diferentes perspectivas y acercamientos metodológicos las dinámicas y magnitudes de la migración de retorno de la población mexicana. En el presente artículo reflexionamos sobre el retorno contemporáneo en comunidades rurales de los municipios de Coatepec Harinas y Tenancingo, Estado de México, con la finalidad de analizar según las perspectivas de los sujetos migrantes retornados tanto los motivos del retorno, como las interpretaciones que construyen en torno al hecho de volver a casa para quedarse y buscar reinsertarse en los lugares de asentamiento, o bien, emigrar nuevamente para dar continuidad a sus proyectos de vida en Estados Unidos.

Palabras clave: retorno; repatriados; reinserción laboral; Coatepec Harinas; Tenancingo.

\footnotetext{
1 Resultados del proyecto de investigación "Nuevas dinámicas de la migración internacional mexiquense en el contexto de la desaceleración del flujo migratorio México-Estados Unidos". Financiado por la Secretaría de Educación Pública (DSA/103.5/16/10569). Drª . Ana Elizabeth Jardón Hernández-Investigadora responsable.

*Doctora en Ciencias Sociales; Profesora-investigadora en el Centro de Investigación en Ciencias Sociales y Humanidades de la Universidad Autónoma del Estado de México (UAEM), Toluca, Méx, México; E-mail: ileana.14@hotmail.com.

**Doctora en Geografia; Profesora-investigadora en el Centro de Investigación y Estudios en Movilidades y Migraciones Internacionales de la Universidad Autónoma del Estado de México (UAEM), Toluca, Méx, México; E-mail: normabacat@gmail.com
} 
ABSTRACT: During last years, particularly, after the economic crisis in the US during 2008, it aroused a genuine interest for studying, from different perspectives and methodological approaches, the dynamics and magnitude of return migration of Mexican population. In this paper, we reflect on contemporary return in rural communities from the municipios of Coatepec Harinas and Tenancingo, in Estado de México, to analyze, since the perspective of returned subject the raisons of returning and the interpretations that they built around the fact to go back home to stay and look for reintegrate in the places of settlement, or, emigrate again to continue their life projects in the US.

Keywords: return; repatriate; laboral reintegration; Coatepec Harinas; Tenancingo.

RÉSUMÉ: Aux derniers ans, particulièrement après la crise économique de 2008 aux États-Unis, il y a suscité un génuine intérêt pour étudier, dès diffèrent perspectives et approchements méthodologiques, les dynamiques et la magnitude de la migration de retour de la population mexicaine. Dans ce document, on réfléchit sur le retour contemporain aux villages ruraux des municipalités de Coatepec Harinas et Tenancingo, au Estado de Mexico (Mexique), avec la finalité de faire une analyse selon les perspectives des sujets migrants de retour sur les motifs de retourner, et les interprétations qu'ils construisent autour le fait de revenir 'chez-eux' pour rester et chercher l'insertion, ou bien, émigrer un fois encore pour continuer leur projets de vie aux États-Unis.

Mots-clés: Retour; repatriés; réinsertion au travail; Coatepec Harinas; Tenancingo.

RESUMO: Nos últimos anos, particularmente após a crise econômica que os Estados Unidos vivenciaram em 2008, despertouse um interesse genuíno em estudar as dinâmicas e magnitudes da migração de retorno da população mexicana a partir de diferentes perspectivas e abordagens metodológicas. Neste artigo, refletimos sobre o retorno contemporâneo em comunidades rurais dos municípios de Coatepec Harinas e Tenancingo, Estado do México, com o objetivo de analisar, segundo as perspectivas dos sujeitos migrantes que regressaram, as razões de seu regresso, bem como as interpretações que eles constroem. em torno do fato de voltar para casa para ficar e buscar a reinserção nos assentamentos, ou emigrar novamente para continuar seus projetos de vida nos Estados Unidos.

Palavras-chave: retorno; repatriados; reinserção laboral; Coatepec Harinas; Tenancingo. 


\section{INTRODUCCIÓN}

En el año 2002, con la creación del Departamento de Seguridad Nacional (Deparment of Homeland Security), la Unión Americana instauró un nuevo aparato burocrático-administrativo para impulsar una serie de cambios en materia de aprehensiones y deportaciones, que vinieron a impactar en el patrón migratorio México-Estados Unidos, particularmente en la dinámica y las características de la migración de retorno (Gandini et al, 2015).

A partir de ello, y especialmente con la crisis económica mundial de 2008, los estudios enfocados en el análisis del retorno en México adquirieron una importancia mediática ante la posibilidad (alarmista) de que ocurriera un "retorno masivo" de nuestros connacionales (Martínez et al, 2010; Celade, 2010; Cruz y Zapata, 2013). El interés que el tema generó en el ámbito académico fue notable y giró en torno a diferentes tesis, de las que destacan las precisiones del concepto; así como el estudio de las características, tendencias y volúmenes de la población retornada; los motivos del regreso, los impactos de estos desplazamientos y los problemas para lograr una reinserción laboral y social en los lugares de asentamiento (Canales y Meza, 2016).

En el desarrollo de estas investigaciones son diversas las interpretaciones respecto de ¿quiénes son las y los migrantes retornados? ¿cuáles son los motivos que explican el retorno? y ¿cómo se están reinsertando en los mercados de trabajo de los lugares a los que han regresado? Al respecto, se ha precisado la complejidad para definir y explicar el retorno migratorio, como un proceso dinámico que no necesariamente ocurre hacia el lugar de nacimiento, que no siempre es definitivo, como tampoco se trata de un proceso acompañado de la reinserción laboral inmediata.

En el artículo analizamos la experiencia del retorno migratorio y los procesos de reinserción laboral de sujetos migrantes de retorno en comunidades rurales de los municipios de Coatepec Harinas y Tenancingo ubicados en el sur del Estado de México, México. Nuestras interpretaciones las situamos en los debates sobre la confi- 
guración de un nuevo escenario migratorio entre México y Estados Unidos (Durand, 2013; Canales y Meza, 2016; Jardón, 2017), que en relación con nuestro tema de interés identifican una mayor presencia de población mexicana retornada en los últimos años, cuyos regresos vislumbran una decisión fundamentada en circunstancias tanto voluntarias como forzosas debido a diversos factores de índole económica, social y política.

El texto se estructura de cinco apartados. En el primero se realiza una revisión de algunos supuestos implícitos en el concepto del retorno migratorio y los procesos de reinserción laboral vinculados a éste. En el segundo y tercer apartado se señalan los lugares de estudio y la metodología utilizada en la investigación. En la cuarta sección se exponen diversos posicionamientos que subyacen en el discurso de la población migrante de retorno a comunidades del sur del Estado de México, particularmente hacemos referencia a las nociones vinculadas con el retorno al lugar de nacimiento, la definitividad del desplazamiento y la reinserción laboral. Finalmente, establecemos algunas conclusiones generales para reflexionar en la comprensión de dichos procesos de movilidad.

\section{EL RETORNO MIGRATORIO Y LA REINSERCIÓN LA- BORAL}

"Esta falta de un conocimiento teórico del regreso de emigrantes ha obedecido al hecho de que el fenómeno del retorno no ha tenido durante gran parte de su historia -o, así lo ha parecido al menos- ni la magnitud ni la regularidad propias de un movimiento de población en toda regla. Pero, en la actualidad, los desplazamientos de retorno no se nos presentan como hechos aislados o de reducido alcance" (Castillo, 1997, p.31).

A finales de los años noventa, en su texto teorías de la migración de retorno, Castillo (1997) señaló que la comprensión teórica del retorno migratorio se emplazaba como una tarea pendiente en las Ciencias Sociales, debido a que el concepto se utilizó y aceptó de manera sucinta, sin una definición precisa y una discusión rigurosa que 
le otorgara sustento teórico (Pascual de Sans, 1982 citado en Gandini et al, 2015). En años recientes esta perspectiva parece sostenerse entre algunos autores que consideran que el corolario del fenómeno migratorio ha sido atendido de manera tangencial en las teorías vigentes, posicionando al retorno como un capitulo no escrito en la historia migratoria (King, 2002, citado en Moreno y Álvarez, 2017).

En otros términos, se ha señalado que "el concepto de migración de retorno no tiene límites precisos: (pues) son de muy variada índole los movimientos migratorios que podrían caber bajo esta denominación genérica. De aquí, la vaguedad conceptual con que se suelen emplear los muchos sinónimos existentes al respecto: lo mismo se hace uso de la expresión migración de retorno, que de la de reemigración, contracorriente, reflujo, que de otras más o menos parecidas" (Castillo, 1997, p.31). Siendo que:

"Cuando la gente retorna por vez primera a su país -o región- de origen, sólo en este caso se usará el término migración de retorno; cuando la gente se traslada a un segundo destino, emplearemos el término migración de tránsito; cuando se emigra de nuevo al mismo destino después de haber retornado por primera vez, lo denominaremos reemigración; cuando se emigre a un nuevo destino tras haber retornado, lo llamaremos nueva emigración; cuando los movimientos de ida y vuelta entre dos lugares incluyan más de un retorno llamaremos a esto migración circular" (Bovenkerk, 1974, p.5 citado en Castillo, 1997, p.32).

A esta diversidad terminológica utilizada para referirnos al retorno habría que agregar los desafíos que Lesińska (2013, p. 79) identifica para definirlo en un contexto globalizado y de movilidad permanente, en el que el retorno se convierte en una fase fluida del proceso migratorio, es decir, en un conjunto de partidas y regresos que se suceden entre sí. Además, que la población migrante de retorno constituye un grupo extremadamente heterogéneo dados los diferenciales en las experiencias migratorias, tiempos de la migración, estatus legal, recursos para moverse, motivaciones y proyectos del retorno (Cassarino, 2004, p.270). 
De lo anterior podemos decir que en los estudios sobre migración internacional se ha hecho explícita la complejidad de definir el retorno (Lozano y Martínez, 2015), pero también se identifica un amplio consenso para entenderlo como un elemento del proceso y proyecto migratorio de toda persona migrante, que nos requiere conocer las condiciones en las que retornan los migrantes, los factores que influyen en la decisión, los determinantes del retorno, la dimensión temporal, el lugar del que retornan y el lugar al que retornan (Orrego y Martínez, 2015, p.31).

En concordancia con estos planteamientos, Gandini, Lozano y Gaspar (2015) advierten que la complejidad y el dinamismo de los procesos migratorios precisan superar la noción de las movilidades como un único desplazamiento, y en su lugar pensarla como una sucesión de eventos o traslados en los que el retorno no es visto como momento conclusivo, sino como una parte del hecho migratorio en su totalidad.

De ahí que en un lapso de poco más de tres décadas en las que diversos estudios han contribuido al análisis del retorno, al día de hoy se registran avances importantes en la explicación de dicho proceso. Sin embargo, las definiciones hasta ahora establecidas no son del todo explícitas en la delimitación de los criterios de inclusión y exclusión acerca de ¿qué población es migrante de retorno? y ¿cuál no? Para ello, Gandini et al, (2015) consideran necesario profundizar en por lo menos los siguientes cuatro supuestos implícitos en los conceptos del retorno: (1) ideología nacionalista; (2) territorialidad; (3) temporalidad y (4) motivos y población.

En torno a la ideología nacionalista como un encuadre de pertenencia y lealtad a un Estado-Nación diversos estudios sobre retorno aceptan el supuesto de que el regreso ocurre a un lugar o zona de origen, es decir, al país de nacimiento de esta población. Esto aparentemente precisa no sólo un "sentido de pertenencia" y de arraigo, sino "obligaciones" que las personas tienen con su tierra o país natal, así como un "regreso a casa" que mucha de las veces pierde sentido, particularmente cuando se trata de personas que han vivido fuera por un largo periodo de tiempo, y que, en consecuencia, habrán de enfrentar dificultades diversas en sus procesos de inserción, reinserción y readaptación al entorno al que están regresando. 
Dicho de otra manera, volver a casa no necesariamente implica regresar a los orígenes familiares y al lugar natal, sino reinsertarse socialmente, porque, así como ocurrió con la emigración a un destino internacional, el migrante de retorno puede ser un extranjero en su propia tierra, al grado tal de hacerse necesario un proceso de readaptación-adaptación y resocialización (Rivera, 2015, p.246).

Estrechamente vinculado con el tema de la unidad territorial se asume también que el retorno generalmente ocurre al "lugar de origen", mismo que probablemente no es el lugar de salida previo a la emigración; luego entonces, por contradictorio que parezca puede ocurrir el "regreso a otro lugar" (Masferrer, 2014), cuando el origen (lugar de salida) no es destino (lugar de llegada), por factores diversos, entre los que Masferrer (2012, p.46) identifica las mismas causas que motivaron la emigración, en tanto los cambios que experimentan y las oportunidades que ofrecen determinados territorios trascienden en las opciones de destino al momento de regresar a un determinado país.

A pesar de ello, en la mayor parte de los estudios, la migración de retorno alude a movimientos que ocurren en determinados espacios que son puntos de origen y de regreso para la población que salió de esos territorios. De acuerdo con Rivera (2011), ello supone que las personas que retornan no sólo regresan a su localidad de origen, sino que además lo hacen de manera permanente para reinsertarse en la dinámica económica, social y cultural de dichos espacios.

Por su parte, la temporalidad se vincula con el tiempo de estancia que se ha estado fuera del país de nacimiento, así como con el tiempo de permanencia en determinado lugar. Al respecto, surge como interrogante ¿después de cuánto tiempo es posible considerar que una persona es migrante de retorno? En la complejidad que supone abordar estos aspectos, conviene aclarar que la temporalidad nos obliga a pensar en el retorno no como la última fase del fenómeno migratorio, sino más bien como un proceso que ocurre dentro de los propios procesos de movilidad. Por tanto, los desplazamientos asociados con el retorno difícilmente pueden interpretarse como el reverso de la migración original, y mucho menos como un proceso de temporalidad definitiva. 
Finalmente, reconocer la diversidad de los motivos a los que responde el retorno implica entonces considerar no sólo a las personas que regresan después de haber trabajado en otro país, sino también a las que regresan por motivos tan diversos como son cuestiones familiares $u$ otros aspectos que no necesariamente se vinculan con el componente económico. Sobre esto último, la involuntariedad como característica del retorno contemporáneo cobra importancia para comprender y delimitar los factores a los que responde este proceso, toda vez que la presencia cada vez mayor de personas migrantes retornadas ha puesto de manifiesto que la decisión de retornar "ya no se trata de una acción planeada mediante acumulación de ahorros, sino a menudo precipitada por el despido o la deportación; lo que hace que los migrantes no regresen en condiciones favorables que les permitan reinstalarse" (Mestries, 2013, p.183).

Luego entonces, entre los motivos del retorno contemporáneo puede decirse que el regreso forzado no es exclusivo de la población deportada y repatriada, dado que la "involuntariedad" acuñada al desplazamiento de éstos últimos está presente también entre los que 'deciden' regresar 'voluntariamente' a causa de diversos factores económicos, sociales y políticos, entre los que podemos citar el temor a ser deportado (Mestries, 2013), entre otros muchos miedos como la separación familiar y la pérdida de las pertenencias adquiridas en ese país. En otras palabras, advertimos que la voluntariedad del retorno no es del todo excluyente de otros motivos con tintes más bien involuntarios y forzosos.

A decir de Mestries (2013, p.178), la complejidad en los motivos del retorno radica en que involucran e interconectan factores objetivos y subjetivos; los primeros ligados al migrante y al entorno del qué es parte, y los subjetivos responden a cuestiones derivadas del propio proyecto migratorio, identidad comunitaria, atracción al pueblo de origen, entre otros. Al respecto, Rogers (1984 citado en Cassarino 2004, p.270) planteó por lo menos hace tres décadas que el retorno responde a diversos motivos que incluso se sobreponen los unos con los otros.

En el caso de la dinámica migratoria México-Estados Unidos en mucho favorecida por la vecindad geográfica, que ha hecho de este fenómeno un proceso social masivo e histórico (Durand, 2000), es 
probable que en el análisis de estos desplazamientos a los que denominamos sin distingo alguno "migración de retorno" nos encontremos con una amalgama de movilidades diversas, que bien nos permiten hablar, como lo sugiere Bovenkerk (1974 citado en Castillo, 1997) de retorno, reemigración, nueva emigración y migración circular.

Así las cosas, consideramos que la complejidad para analizar dicho concepto no necesariamente hace parte de las muchas definiciones hasta ahora establecidas, pues más bien son los contextos en tiempo-espacio y las dinámicas de las poblaciones de estudio las que determinan las tantas formas en las que entendemos y construimos el retorno. Por ejemplo, Durand (2004), señala que el retorno no es un proceso automático, sino un proceso de toma de decisiones y de evaluaciones personales y familiares que se mueven en una balanza de costo-beneficio, que por un lado tiene su componente económico y de movilidad social, y por otro, el costo psicológico de la ausencia, la añoranza, la soledad y las dificultades de adaptación a una sociedad diferente.

En otras palabras, la decisión de retornar (aunque pudiera ser la idea de la mayor parte de los migrantes) está vinculada entre otros factores con el ciclo de vida del migrante y su familia, las aspiraciones, la integración, el arraigo y los vínculos con sus lugares de origen. Es por ello que el migrante que piensa en volver mantiene sus vínculos con su comunidad de origen, cuida sus relaciones e incrementa su capital social, que le será útil en caso de emprender una nueva aventura migratoria, pero ahora de regreso al lugar de salida (Durand, 2004). Estos argumentos vistos desde la perspectiva teórica transnacional y la teoría de las redes sociales ayudan a entender que el retorno no constituye el fin del proyecto migratorio, sino por el contrario es parte de un sistema circular de relaciones económico-sociales y de intercambios que facilitan la reintegración de la población migrante (Cassarino, 2004, p.262).

El tema adquiere mayor complejidad en la búsqueda por construir tipologías del retorno, pues los esfuerzos de clasificación de los muchos motivos vinculados con estos procesos de movilidad han cuestionado también los criterios que distinguen un retorno definitivo o temporal y/o un retorno voluntario e involuntario. Entre las 
tipologías utilizadas con mayor frecuencia en México se encuentra la de Durand (2004, 2006), quién plantea los siguientes tipos: i) retorno definitivo y voluntario, que son quienes han decidido regresar a su lugar de origen sin el deseo de verse inmersos en un nuevo movimiento migratorio y con sus propios recursos; ii) los trabajadores temporales, que se encuentran bajo un acuerdo binacional de programas temporales y permisos para trabajar durante ciertos periodos del año; iii) el retorno transgeneracional, que hace alusión a la segunda o tercera generación de los que emprendieron la primera migración, se trata entonces de personas que nacieron en el lugar de destino y regresan al lugar de origen de los padres; iv) el retorno por condiciones forzadas, que incluye a los que se encuentran en un estatus de migración no registrada o clandestina y que son capturados y deportados de manera obligada y/o por alguna reforma migratoria del lugar anfitrión; y v) el fracasado, que no cumplió con las expectativas que tenía al momento de emprender la migración.

De una manera más específica, Bogardus (1934 citado en Alanís, 2015, p.35) expuso la siguiente clasificación para las personas que "estaban regresando" de Estados Unidos a México: “i) los deportados por autoridades de una ciudad, condado y los gobiernos estatales o una combinación en la que participan los tres niveles; ii) los que regresaron voluntariamente, iii) los regresos inducidos o por coerción por el desempleo, la xenofobia y la violencia, iv) las repatriaciones organizadas por agencias privadas y civiles de beneficencia pública y v) las coordinadas por los condados". ${ }^{2}$ Es importante señalar que las tipologías de ambos autores incluyen los retornos voluntarios y forzosos como dos modalidades a las que responde la presencia de estos desplazamientos.

Regresar de manera forzada, como es el caso de los muchos retornados a México en los últimos años nos requiere reconocer que se trata de un grupo de "población de retorno más vulnerable o ya

2 De acuerdo con Alanís (2015, p.33-35), se ha dado un uso poco preciso al concepto de repatriado, generalmente utilizado para referirnos a las personas que entraron al territorio nacional después de haber trabajado o vivido en Estados Unidos por algún tiempo, las que llegaron después de haber sido deportadas e incluso aquellas que fueron apoyadas por algún condado estadounidense para ir a México. En otros términos, el concepto parece aludir a las personas que habían vivido en un país extranjero y regresan con el propósito de establecerse, sin importar si regresaron por su voluntad o habían sido deportados por autoridades extranjeras. 
vulnerada la que intenta reinsertarse en la sociedad y en el mercado de trabajo mexicano. Situación que no puede ser desestimada por el gobierno mexicano si desea que el proceso de integración de estas personas sea satisfactorio" (Gandini et al, 2015, p.161).

A partir de este último argumento emerge la importancia de reflexionar en la reinserción laboral de esta población, entendida como un "proceso posterior al retorno durante el cual los emigrantes no sólo retornan y se reincorporan a la comunidad de la que salieron, sino que buscan dar continuidad a su trayectoria laboral a través de actividades dirigidas a la búsqueda de empleo o bien a la instalación de pequeños negocios en el lugar de origen" (Anguiano et al. 2013, p.117).

Con el retorno lo primero que afrontan las personas migrantes es una realidad un tanto distinta a la que dejaron, tanto en el ámbito familiar, como en el económico. Surge entonces la necesidad de generar ingresos y de buscar una reinserción laboral inmediata, que le permita cubrir sus principales gastos de subsistencia y de ser posible generar ahorro para continuar formando patrimonio (Corona, 2018, p. 460).

Los recursos para lograr dichos procesos de reinserción son diversos e incluyen desde las oportunidades económico-laborales que ofrece el lugar de retorno, la presencia de redes sociales, las trayectorias laborales y la experiencia adquirida, hasta la imaginación, inventiva y el capital económico y humano que posibilita la reinserción e inclusión en la dinámica local (Rivera, 2011).

A pesar de las diversas estrategias que pudieran posibilitar la reinserción laboral son muchas las dificultades que habrán de enfrentar los sujetos migrantes retornados. Además que éstas serán mayores según el tiempo de estancia en el extranjero y las características y oportunidades del contexto al que retorna (Cassarino, 2004). En el ámbito rural mexicano el escenario no es del todo alentador debido al abandono del campo reflejado en la ausencia de políticas focalizadas y la reducción del presupuesto público para éste (Martínez y Vallejo, 2016; Rojas, 2009). La disminución de la producción agrícola como medio de sustento se agrava con la crisis de violencia y problemas de narcotráfico registrada en localidades rurales (Ruvalcaba, 2004). En este contexto otro tipo de problemáticas que no facilitan la reinserción 
laboral tienen que ver con las propias características de los sujetos migrantes que retornan (edad, experiencia laboral, conocimientos/habilidades, condición de ahorro), así como con las condiciones del retorno y las afectaciones a la salud que pueden experimentar estos migrantes por la condiciones de vida y trabajo en EU, pero también por las afectaciones emocionales derivadas de la detención y el retorno forzado a México (Velasco y Coubès, 2013; Romo, 2018).

A estas dificultades se suman otros factores que obstaculizan la inserción laboral de los retornados, tales como la discriminación basada en la edad, la dificultad para acreditar experiencia y antigüedad laboral, además que sus conocimientos, habilidades y trayectoria migratoria incide para que la población local distinga a estos migrantes como rivales con los que habrán de competir laboralmente (Padilla y Jardón, 2014).

Reflexionar sobre algunos de los supuestos implícitos en el concepto del retorno migratorio es entonces el tema de interés de este trabajo, con miras a precisar las connotaciones que adquieren según las perspectivas de la población migrante retornada en comunidades rurales del Estado de México. En otras palabras, buscamos comprender desde las propias interpretaciones de la población migrante ¿qué es el retorno? ¿cuáles son los motivos asociados con este fenómeno? y ¿cómo están participando en los mercados laborales de los lugares a los que han regresado?

\section{LUGARES DE ESTUDIO: COMUNIDADES RURALES EN MUNCIPIOS DEL ESTADO DE MÉXICO}

De ser considerada una entidad de migración emergente, hoy en día, el Estado de México se sitúa en la cuarta posición a nivel nacional entre los estados con mayor emigración al vecino país del norte (Montoya, et al, 2011), antecedido únicamente por Guanajuato, Michoacán y Jalisco, todas entidades de fuerte e histórica tradición migratoria. Por lo cual, consideramos que el tema del retorno en territorios como el Estado de México reviste importancia ante su posicionamiento como expulsor de población migrante internacional (Figueroa y Pérez, 2011) y de migrantes retornados, en los que ubicamos hombres y mujeres que en muchos casos se han visto obligados a regresar. 
A manera de ejemplo, la Unidad de Política Migratoria de la Secretaría de Gobernación reportó un estimado de 10,480 eventos de repatriación ${ }^{3}$ de población mexiquense en 2016, cantidad que representó alrededor de 5\% del total de eventos contabilizados en ese año $(219,905)$ y que ubicaron a la entidad mexiquense en la octava posición a nivel nacional (ver cuadro 1). En 2017, se registró una menor cantidad en la presencia de dichos eventos, lo que no resta importancia debido a las muchas problemáticas que trae consigo el retorno forzado de estas personas migrantes.

Cuadro 1. Eventos de repatriación de población originaria del Estado de México, 2016-2017

\begin{tabular}{|c|c|c|c|c|c|c|}
\hline \multirow{3}{*}{ Concepto } & \multicolumn{6}{|c|}{ Año } \\
\hline & \multicolumn{3}{|c|}{2016} & \multicolumn{3}{|c|}{2017} \\
\hline & Hombres & Mujeres & Total & Hombres & Mujeres & Total \\
\hline Nacional & 197,002 & 22,903 & 219,905 & 152,168 & 14,818 & 166,986 \\
\hline Estado de México & 9,414 & 1,066 & 10,480 & 7,095 & 585 & 7,680 \\
\hline Porcentaje & \multicolumn{3}{|c|}{4.7} & \multicolumn{3}{|c|}{4.5} \\
\hline Posición & \multicolumn{3}{|c|}{8} & \multicolumn{3}{|c|}{9} \\
\hline
\end{tabular}

Fuente: Elaboración propia con base en estadísticas de la Unidad de Política Migratoria, 2017.

Por otra parte, el índice de intensidad migratoria estimado por el Consejo Nacional de Población ${ }^{4}$ muestra que la entidad mexiquense experimentó cambios en la proporción de viviendas con migrantes retornados, pasando de aproximadamente $0.3 \%$ a $1.1 \%$ entre los quinquenios $1995-2000$ y $2005-2010 .{ }^{5}$

3 Las cifras se refieren a eventos debido a que una persona puede ser repatriada en más de una ocasión. 4 El índice de intensidad migratoria se construye a partir de la muestra del diez por ciento del Censo de Población y Vivienda 2010 y concentra los siguientes cuatro aspectos:

-Viviendas que reciben remesas (ingresos procedentes del exterior).

-Viviendas con emigrantes a Estados Unidos durante el quinquenio 2005-2010 que a la fecha del levantamiento censal permanecían en ese país (emigrantes).

-Viviendas con migrantes a Estados Unidos durante el quinquenio 2005-2010 que regresaron al país durante ese mismo periodo (migrantes circulares) y que a la fecha del levantamiento censal residían en México; y -Viviendas con migrantes que residían en Estados Unidos en 2005 y regresaron a vivir a México antes del levantamiento censal de 2010 (migrantes de retorno).

Cabe señalar que el objetivo del índice de intensidad migratoria México-Estados Unidos es captar la intensidad y no la magnitud del fenómeno. Por ello, las viviendas se consideran una sola vez en cada uno de los indicadores, sin importar si más de un miembro de la vivienda recibe remesas o experimentó el evento de cualquiera de las tres modalidades migratorias consideradas en el índice (CONAPO, 2012a, p. 27).

5 En el año 2010 el Estado de México registró un índice de intensidad migratoria de 0.90. Valor con el que obtuvo un grado de baja intensidad migratoria y se situó en la posición número 24 a nivel nacional. Además, el indicador de vivienda con migrantes de retorno en el Estado de México 
En un esfuerzo por entender las lógicas relacionadas con este proceso realizamos un acercamiento a los municipios de Coatepec Harinas y Tenancingo, en los que la proporción de viviendas con población migrante retornada dista significativamente entre sí, aunque en ambos casos se sitúa por encima del valor registrado en la entidad mexiquense durante el mismo periodo de tiempo (ver cuadro 2 ). ${ }^{6}$

Cuadro 2. Cambio en la proporción de viviendas con migrantes de retorno en Coatepec Harinas y Tenancingo, Estado de México, 2000 y 2010

\begin{tabular}{|c|c|c|c|c|}
\hline \multirow{3}{*}{ Municipio } & \multicolumn{4}{|c|}{ Viviendas con migrantes de retorno } \\
\hline & \multicolumn{3}{|c|}{ Año } & \multirow{2}{*}{ Diferencia porcentual } \\
\hline & 2000 & $(\%)$ & 2010 & \\
\hline Coatepec Harinas & \multicolumn{2}{|c|}{3.7} & 8.5 & 4.8 \\
\hline Tenancingo & \multicolumn{2}{|c|}{0.4} & 2.2 & 1.8 \\
\hline Estado de México & \multicolumn{2}{|c|}{0.3} & 1.1 & 0.8 \\
\hline
\end{tabular}

Fuente: Elaboración propia con base en los Censos de Población y Vivienda $2000 \mathrm{y}$ 2010, INEGI.

Para reflexionar en los cambios observados en este proceso realizamos una indagatoria con población retornada en comunidades rurales de los municipios de Tenancingo y Coatepec Harinas. Algunas de las localidades que registran la presencia de migrantes retornados son las siguientes: Santa Cruz Quetzalapa, Terrenate, Tecomatlán, San Simonito y Tepetzingo en el municipio de Tenancingo; así como Las Vueltas, El Potrerito, Llano Grande, Piedras Anchas, San Simón el Alto e Ixtlahuaca de Villada en el municipio de Coatepec Harinas.

Para una breve aproximación a estas comunidades rurales presentamos dos ejemplos: Las Vueltas en Coatepec Harinas y Santa Cruz Quetzalapa en el municipio de Tenancingo. Las Vueltas como cualquier otro pueblo de migrantes en México ha venido registrando un proceso de despoblación, que como fenómeno demográfico puede estar relacionado con la movilidad espacial de sus habitantes,

se encuentra por debajo del promedio estatal, que en el mismo año fue de 2.46 (CONAPO, 2012b). 6 Con base en las estimaciones de CONAPO, en el año 2000, el municipio de Coatepec Harinas se posicionó como el único de los 122 municipios del Estado de México con intensidad migratoria de grado "muy alto" (2.04). En 2010, los cambios observados en la dinámica migratoria de su población lo ubicaron en la segunda posición de 125 municipios, con una intensidad alta (6.57). Mientras que el municipio de Tenancingo registró una intensidad migratoria de grado bajo en los años 2000 (0.22) y 2010 (1.31). Es importante mencionar que ambos municipios se ubican en la región sur de la entidad mexiquense, caracterizada por una dinámica migratoria que no es reciente, sino que incluso ha trascendido en la configuración de comunidades transnacionales, así como en la creación de clubes de migrantes en ambos casos (Jardón, 2017, González, 2006). 
específicamente hacia Estados Unidos (Jardón, 2017). De acuerdo con los Censos de Población y Vivienda esta localidad contaba con aproximadamente 1,220 habitantes en 1990; 1,155 personas en 2000 y 841 en 2010. A diferencia por ejemplo de Santa Cruz Quetzalapa que registró 963 habitantes en el año 2000 y 1,080 en 2010.

Otra forma, aunque indirecta, para aproximarnos a los procesos de movilidad de la población en estas localidades tiene que ver con la diferencia porcentual entre viviendas totales y viviendas habitadas, que en nuestros casos queda de la siguiente manera (ver cuadro 3):

Cuadro 3. Viviendas habitadas en localidades de Coatepec Harinas y Tenancingo, Estado de México, 2010

\begin{tabular}{c|c|c|c}
\hline Localidad & $\begin{array}{c}\text { Total de } \\
\text { viviendas }\end{array}$ & $\begin{array}{c}\text { Viviendas } \\
\text { habitadas }\end{array}$ & Porcentaje \\
\hline Las Vueltas & 404 & 219 & 54.7 \\
\hline Santa Cruz Quetzalapa & 290 & 234 & 80.6 \\
\hline
\end{tabular}

Fuente: Elaboración propia con base en los resultados por localidad, ITER 2000 y 2010, INEGI.

Además de lo anterior se registran importantes diferencias en las actividades económicas, pues mientras que en Coatepec Harinas destaca la agricultura, en Tenancingo predominan el comercio y los servicios. Factor que a su vez incide en el ingreso monetario de esta población. Finalmente, consideramos pertinente mencionar que el pueblo de Las Vueltas no cuenta con sistema de transporte público y el traslado a la cabecera municipal toma un tiempo de aproximadamente treinta minutos, no así en el caso de Santa Cruz Quetzalapa que se encuentra comunicada y próxima tanto a la cabecera municipal, como a otras localidades de Tenancingo. En suma, se trata de contextos rurales, cuyas condiciones estructurales ofrecen una cartera de oportunidades no del todo alentadoras para la población retornada. Escenario que está provocando que "el retornado que llega a México de manera voluntaria o forzada enfrente un proceso no fácil de reintegración familiar, social, cultural y económica (Corona, 2018, p.460). 


\section{ALGUNAS CONSIDERACIONES METODOLÓGICAS}

El desarrollo de esta investigación se sustenta en un acercamiento metodológico que incluye el uso de herramientas cuantitativas y cualitativas, que nos permitieron recuperar información estadística para caracterizar a la población de estudio, así como incorporar las voces y perspectivas de los sujetos migrantes en comunidades rurales.

El trabajo de campo se realizó en el periodo enero-agosto 2017. Además del diario de campo, los recorridos hechos en las diversas comunidades de ambos municipios y las charlas informales sostenidas con la población retornada a estos espacios, se diseñó un cuestionario semiestructurado, con la finalidad de identificar las experiencias de los sujetos migrantes de retorno en comunidades rurales del sur del Estado de México.

A través de esta herramienta buscamos ahondar en la comprensión que la población tiene sobre el retorno, los motivos del retorno y los procesos de reinserción laboral a los lugares de regreso. Este instrumento se aplicó tanto a migrantes deportados/repatriados como de regreso voluntario, con el fin de explorar experiencias diversas que suponen un "regreso a casa" aunque no necesariamente un regreso definitivo. Para tal efecto, se aplicaron 48 cuestionarios: 30 entre la población retornada a comunidades rurales de Coatepec Harinas y 18 en Tenancingo, Estado de México.

Cabe mencionar que en ambos municipios se contó con el apoyo de la Dirección de Desarrollo Social para facilitar las entrevistas con hombres y mujeres migrantes originarios de diferentes localidades, que en enero de 2017 recibieron apoyo para impulsar proyectos productivos a través del Programa Fondo de Apoyo al Migrante. En tal sentido, los criterios de selección de los sujetos migrantes fueron los siguientes: i) registrar experiencia de un retorno voluntario y/o de deportación en los últimos años, particularmente del año 2008 en adelante, ii) contar con experiencia laboral en Estados Unidos, iii) incorporación en por lo menos un empleo posterior al retorno, iv) ser beneficiario del Programa Fondo de Apoyo al Migrante y encontrarse en el proceso de implementación de un proyecto productivo. 


\section{ACERCAMIENTO AL RETORNO CONTEMOPORÁNEO EN COMUNIDADES RURALES}

A partir de la información obtenida en campo exponemos primero un breve perfil de nuestra población objetivo. De las 48 personas entrevistadas en Coatepec Harinas y Tenancingo tenemos que $85.4 \%$ son hombres y $14.6 \%$ mujeres, con una edad media de 37 años, esto es una edad plenamente productiva. Alrededor de $83.3 \%$ son casados o unidos, $10.4 \%$ solteros y $6.3 \%$ separados o divorciados. Entre los principales niveles de estudio se encuentra la primaria (50.0) y la secundaria (37.5\%).

De esta población estimamos que $77.0 \%$ permaneció varios años en el vecino país del norte y el restante $33.0 \%$ lo hizo sólo durante algunos meses (menos de un año). En el primer caso encontramos que la mayor parte estuvo entre 1 y 2 años (37.8\%), seguido por las estancias de más de 10 años en ese país (21.6\%) (ver gráfica 1).

Gráfica 1. Tiempo de estancia en Estados Unidos, según años de permanencia de la población retornada a Coatepec Harinas y Tenancingo, Estado de México, 2017

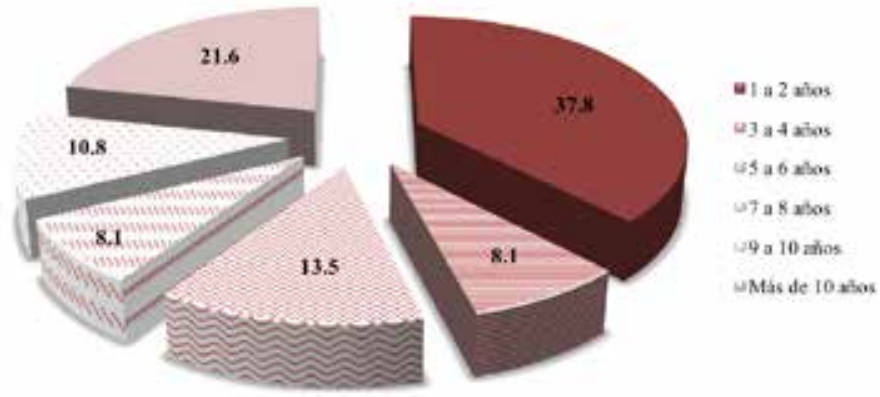

Fuente: Elaboración propia con base en trabajo de campo, enero-agosto 2017.

Es decir, se trata de estancias prolongadas que parecieran apostar más bien por una emigración permanente en Estados Unidos y un retorno forzado a México, o bien de estancias prolongadas con 
el fin de acumular capital para regresar con recursos que faciliten el emprendimiento de iniciativas de desarrollo. No obstante, entre las personas migrantes entrevistadas podemos decir que el retorno viene a representar un conjunto de procesos complejos en la reinserción social y laboral ante el objetivo de "mudar el hogar al norte y construir proyectos de vida volcados hacia la permanencia en Estados Unidos" (Alarcón et al, 2012, p.370).

En los motivos del retorno resaltan dos aspectos: la deportación (45.8\%) y el deseo de estar con la familia en México (27.1\%). En menor proporción se registran factores como la falta de trabajo o despido laboral en Estados Unidos, la deportación del esposo, la salida voluntaria y la decisión de regresar a causa del miedo y la discriminación vivida en ese país (ver gráfica 2).

Gráfica 2. Motivos del retorno de la población en comunidades de Coatepec Harinas y Tenancingo, Estado de México, 2017

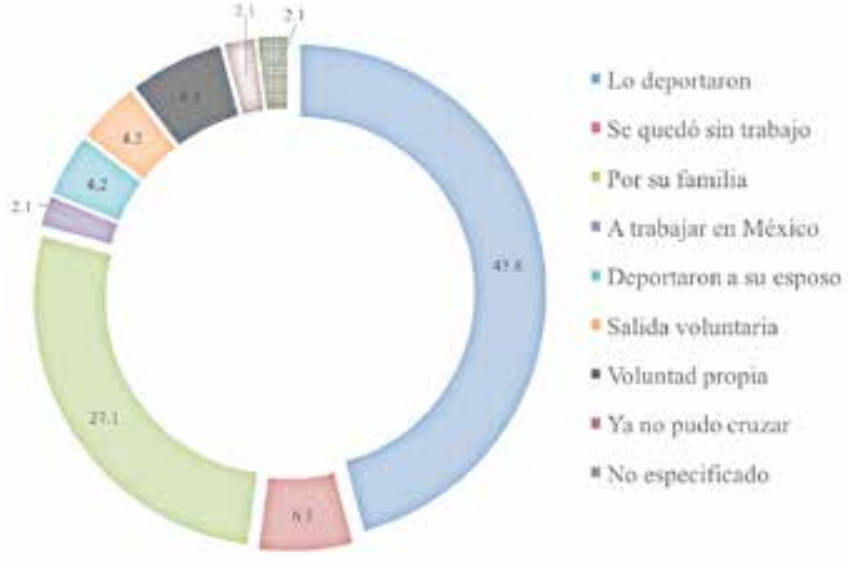

Fuente: Elaboración propia con base en trabajo de campo, enero-agosto 2017.

De los motivos expuestos por los sujetos migrantes entrevistados podemos destacar por lo menos tres anotaciones: la primera tiene que ver con la involuntariedad en los regresos forzados de estos sujetos migrantes rurales deportados; característica que sin duda viene a ser parte del retorno contemporáneo rural. El segundo señalamiento se relaciona 
con los motivos no siempre explícitos y ocultos en el decir "regresar para estar con la familia". Nos referimos a esto, pues las entrevistas nos permitieron identificar que el uso de esta declaración es más bien un pretexto para justificar un retorno que encubre motivos diversos, que van desde la vergüenza a reconocer que han sido deportados, hasta el hecho de haberse quedado sin trabajo, sentir miedo y muchos otros tantos motivos que alimentan esta noción de la involuntariedad y el regreso forzado en un contexto económico, social y político no del todo favorecedor para la población migrante en Estados Unidos.

Como ejemplo citamos el caso de Mirna, mujer tenancinguense que emigró a Estados Unidos para seguir a su esposo y después de haber vivido aproximadamente 15 años en Estados Unidos regresó a México concibiendo su retorno como una decisión fundamentada en circunstancias tanto voluntarias como forzosas: siendo la familia su motivo para regresar por cuenta propia y el contexto político-antiinmigrante el que la obligó a tomar dicha decisión ante el miedo a la deportación y separación de sus hijos:

“ya estando allá (en Estados Unidos) yo decidí regresarme voluntariamente y forzosamente (año 2010), voluntariamente porque en ese tiempo andaba migración muy fuerte, andaba haciendo redadas en muchos lugares, semáforos donde era la oportunidad de ellos (agentes de migración) para atraparnos, pues no me tocó esa experiencia de que nos agarrará migración y nos deportara, pero era cuestión de decidir salir o quedarnos y arriesgarnos a que nos agarraran y si nos agarraban ¿pues qué iba a pasar con nuestros hijos? La verdad mi retorno fue casi que forzoso, yo lo veo de esa manera, porque para no ser deportada y detenida por migración pues tuvimos que separarnos, yo me vine con mis niños y mi esposo se quedó allá (en Estados Unidos) pese a las circunstancias que se vinieran, se quedó allá y se tuvo que cambiar de Estado porque en Illinois estaba muy fuerte migración. Pero a los dos años de cuando yo me vine el decidió venirse (año 2012), pero al ver que aquí (en Tenancingo) es muy difícil intentó regresar otra vez (a Estados Unidos) y ahí fue cuando migración lo agarró y estuvo casi tres meses encerrado" (Mirna, trabajo de campo, agosto 2017). 
Una última anotación tiene que ver precisamente con la noción de regresar por motivos tales como quedarse sin trabajo y la deportación de algún familiar, pues en todo caso se trata de causales que se abrevian nuevamente en la modalidad de retorno forzado.

Sobre las causas del retorno advertidas por esta población es que nos interesa poner el acento, con la finalidad de acercarnos a sus experiencias del retorno, particularmente de la población deportada, cuyo regreso puede no significar un retorno definitivo. Para ello, en los siguientes apartados presentamos un breve análisis de cuatro elementos que nos permiten abordar algunos de los supuestos implícitos en el concepto de retorno desarrollado anteriormente:

1. Precisiones sobre el retorno a la "comunidad de origen"

2. Posicionamientos respecto del regreso a otro lugar que no es el de origen

3. Consideraciones sobre la definitividad del retorno

4. Reinserción laboral: como un proceso que no siempre ocurre en la inmediatez.

En primer lugar, sin lograr separarnos de los imaginarios sobre el retorno, el reencuentro con la casa y la nostalgia generalmente explícita en las investigaciones sobre retorno, nuestro propio estudio deja ver entre la población migrante rural que el regreso de Estados Unidos al municipio de origen (Coatepec Harinas y Tenancingo) evoca expresiones positivas en la mayor parte de los casos, así como posturas negativas y en algunos casos ambiguas, pues se balancean en ambas direcciones (ver cuadro 4).

Las expresiones positivas en torno al regreso tienen que ver con el hecho de "volver a su país" "al pueblo" o "al lugar de nacimiento" donde está su familia, sus raíces, sus costumbres y sus tradiciones. De tal suerte que en el propio discurso de esta población parece no haber una separación entre la idea de un retorno que sin lugar a dudas significa "volver a casa".

Sin embargo destacan también aspectos negativos que cobran mayor presencia entre la población migrante retornada al munici- 
pio de Tenancingo, con posturas que advierten emociones diversas, como por ejemplo tristeza por encontrarse de regreso en un lugar donde no encuentran empleo y no tienen dinero, así como frustración por no haber logrado el anhelado "sueño americano".

De manera intermedia, se encuentran las y los migrantes que señalan estar contentos de haber regresado a "su tierra" y "su pueblo", aunque no dejan de manifestar su descontento particularmente por las diferencias en la situación económica y las mayores posibilidades que dicen encontrar para salir adelante en Estados Unidos. Al respecto, identificamos en el discurso de esta población una intención y esperanza siempre viva de regresar a Estados Unidos, debido a las carencias y necesidades que difícilmente pueden ser atendidas en los lugares de origen.

Dicho de otra manera, en las interpretaciones de la población entrevistada subyacen contradicciones entre la alegría que evoca regresar al lugar donde están sus raíces y el descontento por permanecer en el pueblo que los expulsó, y de nueva cuenta los incita a iniciarse en la aventura de la emigración. Siendo entonces la reemigración, la nueva emigración o incluso el retorno a otro lugar las posibles alternativas de movilidad de esta población cuyo retorno forzado los ha llevado a establecerse en determinados espacios rurales del Estado de México. 
Cuadro 4. Expresiones relacionadas con el retorno a las comunidades de origen de la población migrante de Coatepec Harinas y Tenancingo, Estado de México

\begin{tabular}{|c|c|c|}
\hline \multirow{2}{*}{ 号 } & \multicolumn{2}{|c|}{ Municipio } \\
\hline & Coatepec Harinas & Tenancingo \\
\hline \multirow{11}{*}{$\begin{array}{l}\sum_{0}^{\infty} \\
\vdots \\
0 \\
0 \\
0\end{array}$} & \multicolumn{2}{|c|}{ FELICIDAD, SATISFACCIÓN, ORGULLO, LIBERTAD, TRANQUILIDAD } \\
\hline & "estoy feliz, con salud y satisfecho" & "contenta por estar con mi familia" \\
\hline & $\begin{array}{l}\text { "no hay como estar en el pueblo, aunque no } \\
\text { haya dólares es uno feliz en su casa, más } \\
\text { libertad" }\end{array}$ & $\begin{array}{l}\text { "alegría por estar de nuevo con mi } \\
\text { familia" }\end{array}$ \\
\hline & $\begin{array}{l}\text { "lo mejor, por mi familia la gente es muy } \\
\text { cálida y se puede salir libremente" }\end{array}$ & \\
\hline & $\begin{array}{l}\text { "feliz, contento de estar de nuevo en mi } \\
\text { país" }\end{array}$ & \\
\hline & $\begin{array}{l}\text { "significa muchísimo porque es el lugar } \\
\text { donde nací" }\end{array}$ & \\
\hline & "llega uno a su tierra" & \\
\hline & $\begin{array}{l}\text { "mucho porque aquí están nuestras raíces, } \\
\text { y familia" }\end{array}$ & \\
\hline & $\begin{array}{l}\text { "regresar feliz para ver a mi familia, me } \\
\text { gusta el pueblo, las tradiciones y la tran- } \\
\text { quilidad" }\end{array}$ & \\
\hline & $\begin{array}{l}\text { "felicidad de estar con mi familia, regresar } \\
\text { al lugar donde nací" }\end{array}$ & \\
\hline & $\begin{array}{l}\text { "lo máximo, es un orgullo regresar al pue- } \\
\text { blo a trabajar" }\end{array}$ & \\
\hline \multirow{6}{*}{ 焉 } & \multicolumn{2}{|c|}{$\begin{array}{l}\text { INCOMODIDAD, INFELICIDAD, INCONFORMIDAD, FRUSTRACIÓN, } \\
\text { DECEPCIÓN, TRISTEZA }\end{array}$} \\
\hline & $\begin{array}{l}\text { "incómodo porque no está la familia junta" } \\
\text { "no me siento muy feliz" }\end{array}$ & $\begin{array}{l}\text { "frustración por no poder cruzar y } \\
\text { no tener más dinero" }\end{array}$ \\
\hline & "al no haber más, queda solo trabajar" & $\begin{array}{l}\text { "decepcionada por no conseguir } \\
\text { empleo" }\end{array}$ \\
\hline & & "económicamente estoy mal" \\
\hline & & "frustrado por no estar allá" \\
\hline & & $\begin{array}{l}\text { "tristeza y frustración por no cum- } \\
\text { plir mi sueño americano" }\end{array}$ \\
\hline \multirow{5}{*}{ 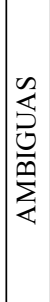 } & \multirow{5}{*}{$\begin{array}{l}\text { "es bonito pero extraño por las posibili- } \\
\text { dades económicas" } \\
\text { "significa que es su tierra, es bonito, pero } \\
\text { no se tiene lo que se tendría allá" } \\
\text { "me siento mejor, estoy con mi familia, } \\
\text { estoy contento, aunque es más difícil que } \\
\text { en E.U porque allá trabajo poco y hay } \\
\text { más dinero" }\end{array}$} & $\begin{array}{l}\text { "me siento bien, lo que no me gusta es } \\
\text { la economía, me gusta la libertad de }\end{array}$ \\
\hline & & mi comunidad, es mi país, mi pueblo" \\
\hline & & "al principio alegría, sin embargo, \\
\hline & & $\begin{array}{l}\text { después de un tiempo tuve deseos de } \\
\text { regresar" }\end{array}$ \\
\hline & & $\begin{array}{l}\text { "en un principio me gustó, pero cuan- } \\
\text { do se terminó el dinero comencé a ver } \\
\text { la necesidad ya que en Estados Uni- } \\
\text { dos los empleos son mejor pagados" }\end{array}$ \\
\hline
\end{tabular}

Fuente: Elaboración propia con base en trabajo de campo, enero-agosto 2017.

En la apuesta por ahondar en los posicionamientos de esta población respecto de regresar a otro lugar que no fuera Coatepec Harinas y 
Tenancingo, encontramos que en su mayoría las expresiones son negativas. En otras palabras, entre nuestra población migrante retornada no se vislumbran preferencias por regresar a otro lugar que no sea su "pueblo" y su "lugar de origen", en el que incluso se sienten arraigados por su familia, sus trabajos actuales y sus propiedades (ver cuadro 5).

A pesar de ello, en el caso de Tenancingo identificamos población que sí considera la posibilidad de establecerse en otro lugar en el que cuente con apoyo de familiares o amigos, es decir con el soporte de las redes sociales que hacen menos tensa la noción de "no tener otro lugar a donde ir" y "no tener otra opción". Esto nos permite inferir que los procesos de movilidad, en la mayor parte de los casos, estarán vinculados con la existencia de redes de apoyo, como un recurso para facilitar y afianzar los procesos de integración en los nuevos lugares de llegada (ver cuadro 5).

Cuadro 5. Posicionamientos respecto de la posibilidad de regresar a otro lugar diferente a Coatepec Harinas y Tenancingo, Estado de México

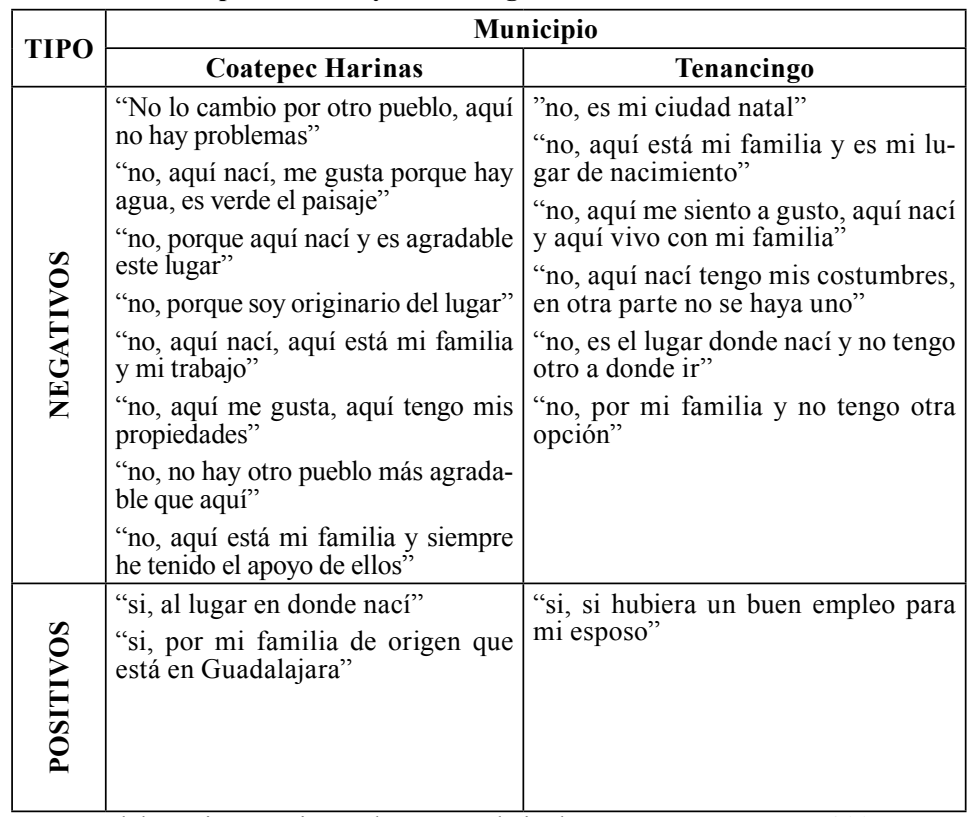

Fuente: Elaboración propia con base en trabajo de campo, enero-agosto 2017. 
Asimismo, aunque son los menos, en el caso de Coatepec Harinas se registró la situación de un migrante cuya localidad de regreso no es el lugar de nacimiento. Con ello y sin la pretensión de hacer generalizaciones reconocemos que existe la posibilidad de que el lugar de regreso no sea siempre el lugar de nacimiento o incluso el lugar de salida, toda vez que en la decisión de retornar entran en juego un conjunto de factores y condiciones que hacen que estos migrantes decidan regresar a otro lugar (Masferrer, 2012).

En cuanto al retorno como la última fase del proceso migratorio algunas tipologías como la que propone Durand (2004) incluyen el regreso por deportación como una modalidad de regreso forzado. En el dilema emigrar o permanecer el autor precisa que "muchos de ellos, intentan otra vez reiniciar el proceso, sobre todo si se trata de migración entre países vecinos o cercanos" (como es el caso México-Estados Unidos), pero al mismo tiempo apunta que "para otros la deportación significa el fin de la carrera migratoria”.

En la experiencia de Sergio, migrante repatriado originario del municipio de Tenancingo, la vecindad geográfica entre México y Estados Unidos hace de la migración internacional una constante, que particularmente en su caso deja de lado el hecho de haber sido repatriado y lo motiva a buscar una nueva oportunidad para regresar al vecino país, por diversas cuestiones, entre las que destaca la posibilidad de vivir mejor, pero también el hecho de "ya no hallarse" en el lugar al que ha regresado (ver cuadro 6).

"Nunca nos van a parar, 'jamás' porque nada más damos la vuelta, cuando no somos unos son otros, no importa lo que digan los presidentes, es la verdad, es lo que se vive, cuando uno está en la frontera. Ahora, cuando tenga la oportunidad de irme (a Estados Unidos) me voy, (porque) yo voy y vengo y así lo siento, así lo veo, si llega otra oportunidad, lo vuelvo a intentar" (Migrante repatriado, 43 años, 2017).

"Yo no he regresado definitivamente porque a pesar del trabajo duro en Estados Unidos, uno quiere volver a trabajar a ganar más, comer bien. Es para mejorar en todo, vivienda, vestuario, alimentación" (Migrante repatriado, 36 años, 2017). 
Cuadro 6. Posicionamientos respecto del retorno como la última fase del proceso migratorio entre la población de Coatepec Harinas y Tenancingo, Estado de México

\begin{tabular}{|c|c|c|}
\hline \multirow{2}{*}{ ?ְ. } & \multicolumn{2}{|c|}{ Municipio } \\
\hline & Coatepec Harinas & Tenancingo \\
\hline \multirow{5}{*}{ 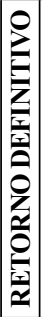 } & $\begin{array}{l}\text { "sí, porque somos de este lugar y } \\
\text { tenemos que regresar al país y no }\end{array}$ & $\begin{array}{l}\text { "si porque es mucho el riesgo ya no se pasa } \\
\text { tan fácil como antes" }\end{array}$ \\
\hline & $\begin{array}{l}\text { tengo papeles" } \\
\text { "sí, porque me sacaron del lugar" }\end{array}$ & $\begin{array}{l}\text { "sí, porque al regresar a México es muy } \\
\text { difícil volver a cruzar" }\end{array}$ \\
\hline & lí y al no encontrar & "si por mi familia" \\
\hline & $\begin{array}{l}\text { puertas abiertas me tuve que ve- } \\
\text { nir" }\end{array}$ & $\begin{array}{l}\text { "sí, como fui deportado me tengo que que- } \\
\text { dar aquí" }\end{array}$ \\
\hline & $\begin{array}{l}\text { "sí, porque ya sea por nuestra vo- } \\
\text { luntad o a fuerza regresamos y so- } \\
\text { mos retornados" }\end{array}$ & "sí, por la edad" \\
\hline \multirow{6}{*}{ 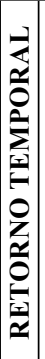 } & $\begin{array}{l}\text { "no, aquí no estoy por mi voluntad" } \\
\text { "no, soy migrante porque quiero } \\
\text { volver" }\end{array}$ & $\begin{array}{l}\text { "no tengo la mentalidad de quedarme, es- } \\
\text { pero una posibilidad de que pueda tener } \\
\text { visa de trabajo" }\end{array}$ \\
\hline & ezco & "no, a mí me gustaría regresar a EU” \\
\hline & $\begin{array}{l}\text { por mi familia, mi esposa está em- } \\
\text { barazada, pero quiero regresar (a }\end{array}$ & $\begin{array}{l}\text { "no, si llega otra oportunidad lo vuelvo a } \\
\text { intentar" }\end{array}$ \\
\hline & Estados Unidos) & "no, en un futuro pienso regresar" \\
\hline & & $\begin{array}{l}\text { "no, me gustaría tener bien mis papeles y } \\
\text { regresar a EU" }\end{array}$ \\
\hline & & $\begin{array}{l}\text { "no, por lo económico y mi familia se en- } \\
\text { cuentra en EU y es otro estilo de vida" }\end{array}$ \\
\hline
\end{tabular}

Fuente: Elaboración propia con base en trabajo de campo, enero-agosto 2017.

A partir de lo anterior consideramos que la repatriación no necesariamente representa el "fin de la carrera migratoria", pues la noción de "ser (soy) migrante y quiero volver (a Estados Unidos)" pone de manifiesto entre esta población que no necesariamente permea una construcción social del retorno como la última fase de sus trayectorias migratorias, como tampoco la definitividad de dicho proceso, puesto que “...muchos tienen idea de volver (a Estados Unidos) y eso es igual a ser 'migrante', (y) si ya piensas quedarte (en México) es igual a (ser) un 'retornado'...” (ver cuadro 6).

Finalmente, están los que consideran que su regreso es definitivo porque se les han cerrado las puertas y las oportunidades en Estados Unidos, así como por la dificultad para cruzar a ese país. Además de otros factores como la falta de documentos para acreditar una estancia legal, la edad y la misma familia por la que deben procurar su bienestar en México.

A manera de resumen, en un esfuerzo por sintetizar y cuantificar los hallazgos derivados de este análisis estimamos que 47 de 48 
migrante regresaron a su lugar de nacimiento en comunidades de Coatepec Harinas y Tenancingo Estado de México. De ellos, la mayoría (36, esto es $75.0 \%$ ) conjuga en su discurso una suerte de emociones, de alegría, satisfacción y disfrute por regresar a su lugar de nacimiento, del que se sienten parte, arraigados y en comunidad (ver cuadro 7).

Cuadro 7. Relación entre los supuestos implícitos en los conceptos del retorno migratorio y el discurso de la población de retorno en comunidades rurales en el Estado de México

\begin{tabular}{|l|l|l|}
\hline \multicolumn{1}{|c|}{$\begin{array}{l}\text { Respecto del } \\
\text { supuesto: }\end{array}$} & \multicolumn{2}{|c|}{ De un total de 48 migrantes retornados: } \\
\hline $\begin{array}{l}\text { Retorno a casa- } \\
\text { comunidad de } \\
\text { origen }\end{array}$ & $\begin{array}{l}47 \text { regresaron a su lugar de } \\
\text { nacimiento. } \\
1 \text { regresó a otro lugar que no } \\
\text { es su lugar de nacimiento. }\end{array}$ & $\begin{array}{l}\text { De éstos: } \\
36 \text { manifiestan alegría y emoción } \\
\text { por retornar al lugar de origen. } \\
12 \text { expresan descontento, frustra- } \\
\text { ción y enojo por regresar a su lugar } \\
\text { de origen. }\end{array}$ \\
$\begin{array}{l}\text { Posibilidad de manifiestan su preferencia y es- } \\
\text { regresar a otro } \\
\text { lugar }\end{array}$ & $\begin{array}{l}\text { tán convencidos de que haber re- } \\
\text { gresado a su lugar de nacimiento } \\
\text { es la mejor decisión. } \\
5 \text { señalaron su preferencia ante la } \\
\text { posibilidad de regresar a otro lu- } \\
\text { gar, que les ofrezca mejores opor- } \\
\text { tunidades. }\end{array}$ \\
\cline { 1 - 2 } $\begin{array}{l}\text { Temporalidad } \\
\text { (definititivad del } \\
\text { retorno - forza- } \\
\text { do) }\end{array}$ & $\begin{array}{l}\text { 16 señalan que su regreso } \\
\text { no se trata de un movi- } \\
\text { miento definitivo, en tanto } \\
\text { albergan la esperanza de } \\
\text { regresar a Estados Unidos. }\end{array}$ & $\begin{array}{l}32 \text { consideran que han regresado } \\
\text { de manera definitiva, por razones } \\
\text { como la deportación y la falta de } \\
\text { documentos. }\end{array}$ \\
\hline
\end{tabular}

Fuente: elaboración propia con base en trabajo de campo, enero-agosto 2017.

Entre estos migrantes rurales apreciamos también que la mayor parte (32 de 48) se pronunció a favor de regresar a su lugar de origen, y no propiamente a otro lugar del que no son y del que no se sentirían parte. Aunque ello no exime que la posibilidad de regresar a otro lugar ocurra en tanto cuenten con redes de apoyo en esos espacios y/o se encuentren con dificultades diversas para reinsertarse en los lugares de regreso. Finalmente, $32(66.6 \%)$ de los encuestados encuentran en su regreso a México un retorno "definitivo" y 16 (33.3\%) de ellos manifestó lo contrario, diciendo estar a la espera de regresar a Estados Unidos apenas cuenten con las posibilidades económicas y el apoyo para hacerlo (ver cuadro 7).

A pesar de las diferentes acepciones sobre las que gira el retorno entre la población entrevistada, la reinserción a los mercados 
de trabajo es un hecho presente en la mayoría de estos hombres y mujeres migrantes. Pues por ejemplo, aproximadamente $60 \%$ buscó trabajo de manera inmediata, en tanto $30.0 \%$ esperó un determinado periodo de tiempo y $4.2 \%$ no buscó opciones para emplearse. Entre la población que no buscó trabajo en lo inmediato estimamos un tiempo de espera de 3.7 meses y de aproximadamente 8 días.

De la población que esperó un tiempo y/o buscó empleo de manera inmediata observamos que $85.7 \%$ pudo obtener empleo y $14.3 \%$ tuvo dificultades para incorporarse laboralmente. Los tiempos de espera para obtener empleo oscilan entre un mínimo de 7 días y máximo de 2.1 meses. Siendo importante el papel que juegan la familia y los amigos, debido a que $30.6 \%$ se apoyó de algún familiar y $25.0 \%$ de sus amistades para encontrar trabajo. Finalmente, el $44.4 \%$ restante mencionó que no requirió ayuda para lograrlo.

Entre enero y agosto de 2017 que entrevistamos a esta población un $92.7 \%$ se encontraba trabajando, desempeñando en su mayoría actividades del campo (42.6\%), la construcción (23.4\%), servicios (19.1\%) y comercio (10.6\%); con jornadas de aproximadamente 46 horas a la semana. De estas 47 personas $76.6 \%$ no tuvo dificultades para conseguir su empleo actual y $22.9 \%$ hizo referencia a dificultades diversas, como por ejemplo la escasa oferta de fuentes de empleos (45.5\%), la falta de trabajos vinculados con lo que saben hacer y/o desean trabajar (2.1) y otras problemáticas (10.4\%), como la edad, falta de dinero y ausencia de redes de apoyo.

Por otra parte, estimamos que $40.4 \%$ de estos migrantes además de desempeñarse en su empleo actual realiza otro tipo de actividades para complementar sus ingresos, en tanto $23.4 \%$ ha estado buscando otro trabajo con la expectativa de mejorar su ingreso (63.6\%), mejorar sus condiciones de trabajo $(27.3 \%)$ y tener un empleo en el que pueda hacer uso de las habilidades y conocimientos adquiridos en Estados Unidos (9.1\%). En otras palabras, estas dinámicas laborales denotan la pluriactividad o diversificación económica que los hogares rurales adoptan para generar ingresos, al mismo tiempo que destacan el papel de la agencia humana, las capacidades y los recursos de los que se apoyan los hogares para elegir mejorar sus condiciones de vida (De Haas, 2010). 
Entre otros aspectos identificamos un alto nivel de conformidad respecto de los empleos en los que se encuentra inserta esta población, en la medida en que $85.1 \%$ mencionó estar satisfecho en su trabajo. Aunque contradictoriamente $66.0 \%$ señaló que cambiaría de empleo si tuviese la posibilidad de acceder a un trabajo con ingresos más altos $(93.5 \%)$ y/o que estuviese cercano a su lugar de residencia (3.2\%).

Alterno a los trabajos realizados por esta población, el total de los sujetos entrevistados ha sido beneficiario del Programa Fondo de Apoyo al Migrante, que otorga ayudas individuales, familiares y grupales, además de promover el desarrollo de cursos de capacitación, con el fin de incrementar las actividades ocupacionales y desarrollar las capacidades técnicas y productivas de los migrantes en retorno (Segob, 2016, 2017).

A pesar de ello, los hallazgos de nuestra investigación nos permiten señalar que se trata de una serie de apoyos de reducido alcance, que no necesariamente están siendo capitalizados y potenciados adecuadamente por situaciones tan diversas entre las que podemos citar: la falta de interés del sujeto migrante cuya intención es regresar a Estados Unidos, la parcialidad del apoyo recibido, la falta de conocimientos técnicos y de la valoración sobre la pertinencia de los proyectos productivos a desarrollar. Entre otros factores que nos permiten argumentar que las propuestas implementadas por el gobierno mexicano para facilitar los procesos de reinserción laboral y el autoempleo precisan de una serie de mejoras en sus procesos de operación, con el propósito de eficientar la asignación de los apoyos y de ampliar su alcance como estrategias para la reinserción laboral de los migrantes retornados.

\section{CONCLUSIONES}

La complejidad que reviste la dinámica migratoria México-Estados Unidos sin duda nos exige avanzar en una reflexión conceptual de la noción del retorno migratorio y de las tipologías construidas para explicarlo, con la finalidad de comprender los atributos que distinguen a estas poblaciones, así como los múltiples y diversos motivos asociados con los retornos forzados, cuya presencia ha cobrado importancia, particularmente en el actual escenario migratorio entre ambos países. 
Avanzar en una comprensión de dicho concepto nos requiere entender que en la búsqueda de oportunidades el retorno de los sujetos migrantes puede ocurrir a otro lugar que no necesariamente es el de origen y/o de salida; al tiempo que la formulación de propuestas para facilitar los procesos de reinserción demandan también la necesidad de establecer criterios de temporalidad, esto es, ¿cuánto tiempo después de haber estado fuera? y ¿cuánto tiempo después de haber permanecido en el lugar al que se ha regresado puede decirse que un migrante ha retornado? Ante ello reconocemos la dificultad para establecer criterios consensuados al respecto, toda vez que los contextos del retorno, las dinámicas y siempre heterogéneas características de la población migrante de retorno hacen de esto una tarea por demás complicada.

Aunado a dicha complejidad, caben las interpretaciones sobre el retorno temporal o definitivo, toda vez que difícilmente puede decirse que los que regresan lo hacen para quedarse, particularmente ante la inquietud de volver a Estados Unidos. Asimismo, entender el retorno en sus acepciones de "voluntario" y "forzado" supone interpretaciones diversas, pues el retorno por falta de empleo puede no ser un regreso voluntario, como las deportaciones pueden no ser retornos definitivos.

Sobre los principales hallazgos que discutimos en este artículo destacamos que la población migrante de retorno encuestada parece construir en la mayor parte de los casos una experiencia de regreso asociada al lugar de nacimiento o al terruño al que se sienten arraigados tanto por la familia, como por las propias costumbres y tradiciones. No obstante, el hecho de regresar incluso por deportación, no necesariamente significa que se ha regresado para quedarse de manera definitiva en ese lugar. En lo que respecta a los procesos de incorporación laboral encontramos que no siempre ocurren en lo inmediato, aunque la mayor parte de la población encuestada trabaja actualmente a pesar de las dificultades que en algún momento limitaron la posibilidad de obtener un empleo.

Conscientes de que los estudios de caso aquí expuestos no se separan de un análisis que aborda el retorno al lugar de origen, consideramos este trabajo como un ejercicio de reflexión que invita al análisis comparado del retorno en comunidades rurales y urbanas, siendo éstas últimas las que posiblemente registren una mayor pre- 
sencia de población retornada "a otro lugar", que no necesariamente es el lugar de salida y de nacimiento de dichos migrantes.

Finalmente, avanzar en la discusión de estas nociones de orden conceptual resulta pertinente para establecer recomendaciones en materia de política pública, en la medida en que la aumentada presencia de población deportada y retornada aumentará las presiones en la demanda de empleo y otros servicios, recreando un conjunto de desafíos que difícilmente el gobierno mexicano está preparado para atender a través de soluciones bien planificadas y sustentadas en bases institucionales y presupuestales sólidas.

\section{REFERENCIAS}

ALANÍS, F. Voces de la repatriación. La sociedad mexicana y la repatriación de mexicanos de Estados Unidos 1930-1933. México: El Colegio de la Frontera Norte, 2015.

ALARCÓN, R. ESCALA, L. y ODGERS, Olga. Mudando el hogar al norte. Trayectorias de integración de los inmigrantes mexicanos en Los Ángeles, México: El Colegio de la Frontera Norte, 2012.

ANGUIANO, M, CRUZ, R. y GARBEY, R. Migración internacional de retorno: trayectorias y reinserción laboral de emigrantes veracruzanos. Papeles de Población, Vol. 19, nº 77, pp.115-147, 2013.

CANALES, A. y MEZA, S. Fin del colapso y nuevo escenario migratorio México-Estados Unidos. Migración y Desarrollo, Vol. 14, nº. 27, pp.27, 65-107, 2016.

CASSARINO, J. Theorising Return Migration: The Conceptual Approach to Return Migrants Revisited. International Journal on Multicultural Societies, Vol. 6, nº. 2, pp 253-279, 2004.

CASTILlO, J. Teorías de la migración de retorno. En IZQUIERDO, A. y ÁlVAREZ, G. (Ed.). Políticas de retorno de emigrantes, 1997.

CENTRO LATINOAMERICANO Y CARIBEÑO DE DEMOGRAFÍA. Impactos de la crisis económica en la migración y el desarrollo. Respuestas de política y programas en Iberoamérica. División de Población de la CPEAL, 2010. En: https://www.cepal.org/cgibin/getProd.asp?xml=/ celade/noticias/documentosdetrabajo/8/40358/P40358.xml\&xsl=/celade/ tpl/p38f.xsl\&base=/tpl/imprimir.xslt accedido el 10 de sep. 2018.

Consejo Nacional de Población. Anexo B. Índices de Intensidad Migratoria México-Estados Unidos por entidad federativa y municipio, $2012 \mathrm{~b}$. In: http://www.conapo.gob.mx/work/models/CONAPO/intensidad_ migratoria/anexos/Anexo_B1.pdf accedido el 10 de sep. 2018. 
Consejo Nacional de Población. Índice de Intensidad Migratoria MéxicoEstados Unidos, 2012a. In: http://www.conapo.gob.mx/work/ models/CONAPO/intensidad_migratoria/pdf/IIM_Generales.pdf accedido el 10 de sep. 2018.

CORONA, M. El arduo proceso de reinserción laboral de los retornados en la periferia globalizada. Economía, Sociedad y Territorio, Vol. XVIII, no. 57, pp.455-486, 2018.

CRUZ, R. y ZAPATA, R. Naturalización y vulnerabilidad de los inmigrantes mexicanos en Estados Unidos. En ANGUIANO, M. y CRUZ, R. (Eds.) Migraciones internacionales, crisis y vulnerabilidades. Perspectivas comparadas, México, El Colegio de la Frontera Norte, 2013.

DE HAAS, H. Migration and Development: A Theoretical Perspective, International Migration Review, Vol. 44, nº 1, pp.227-264, 2010.

DURAND, J. Ensayo teórico sobre la migración de retorno. El principio del rendimiento decreciente. Cuadernos Geográficos, Vol. 35, nº. 2, pp.103-116, 2004.

DURAND, J. Los inmigrantes también emigran. La migración de retorno como corolario del proceso. Revista Interdisciplinar da Mobilidade Humana, Vol. 14, nº. 26-27, pp. 167-189, 2006.

DURAND, J. Nueva fase migratoria. Papeles de Población, Vol. 19, nº. 77, pp.83-113, 2013.

DURAND. J. Tres premisas para entender y explicar la migración MéxicoEstados Unidos. Relaciones, Vol. XXI, nº. 83, pp.19-35, 2000.

FIGUEROA, E. y PÉREZ, F. El proceso de asentamiento de la migración México-Estados Unidos. Papeles de Población, Vol. 17, nº 68, 2011.

GANDINI, L. LOZANO, F. y GASPAR, S. El retorno en el nuevo escenario de la migración México y Estados Unidos, México: Consejo Nacional de Población, 2015.

GONZÁLEZ, J. Migración y remesas en el sur del Estado de México. Papeles de Población, Vol. 12, nº 50, pp.223-252, 2006.

INSTITUTO NACIONAL DE ESTADÍSTICA, GEOGRAFÍA E INFORMÁTICA, Censo General de Población y Vivienda, 2010. In: http://www.beta.inegi.org.mx/proyectos/ccpv/2010/default.html accedido el 8 de ene. 2018.

INSTITUTO NACIONAL DE ESTADÍSTICA, GEOGRAFÍA E INFORMÁTICA, Censo General de Población y Vivienda, 2000. In: http://www.beta.inegi.org.mx/proyectos/ccpv/2000/default.html accedido el 8 de ene. 2018.

INSTITUTO NACIONAL DE ESTADÍSTICA, GEOGRAFÍA E INFORMÁTICA, Censo General de Población y Vivienda, 2000. Principales resultados por localidad (ITER). In: http://www.inegi. 
org.mx/est/contenidos/proyectos/ccpv/cpv2000/iter_2000.aspx accedido el 8 de ene. 2018.

INSTITUTO NACIONAL DE ESTADÍSTICA, GEOGRAFÍA E INFORMÁTICA, Censo General de Población y Vivienda, 2010. Principales resultados por localidad (ITER). In: http://www.inegi. org.mx/est/contenidos/proyectos/ccpv/cpv2010/iter_2010.aspx accedido el 8 de ene. 2018.

JARDÓN, A. International Migration and Crisis. Transition Toward a New Migratory Phase. Estados Unidos, Editorial Springer, 2017.

LESINSKA, M. The Dilemmas of Policy Towards Return Migration. The Case of Poland After the EU Accession. Central and Eastern European Migration Review, Vol. 2, no. 1, pp.77-90, 2013.

LOZANO, F. y MARTÍNEZ, J. Las muchas caras del retorno en América Latina. En: LOZANO, F. y MARTÍNEZ, J. (Eds.). Retorno en los procesos migratorios de América Latina. Conceptos, debates, evidencias. Uruguay, TRILCE, 2015.

MARTÍNEZ, E. y VALLEJO, J. Políticas públicas y parques industriales en dos municipios rurales del centro de México. El caso de las maquilas de confección. En SALAS, H. y PALETA, G. (Eds.). Las transformaciones rurales en la globalización, trabajo, cambios territoriales y ruralidades. Universidad Nacional Autónoma de México, 2016.

MARTÍNEZ, J. REBOIRAS, L. Y CONTRUCCI, M. Crisis económica y migración internacional: hipótesis, visiones y consecuencias en América Latina y el Caribe. Rev. Internacional Movilidad Humana, Año XVIII, no. 35, pp. 45-70, 2010.

MASFERRER, C. Cuando el origen no es destino: ciclo de vida y el retorno como posibles vínculos entre la migración interna e internacional. Coyuntura Demográfica, n.2, pp.45-50, 2012.

MASFERRER, C. De regreso a otro lugar. La relación entre migración interna y la migración de retorno en 2005. En VALDIVIA, M. et al. (Ed.). Análisis espacial de las remesas, la migración de retorno y el crecimiento regional en México. México: Editorial Plaza y Valdés, 2014.

MESTRIES, F. Los migrantes de retorno ante un futuro incierto. Sociológicas, Vol. 28, no․ 78, pp.171-212, 2013.

MONTOYA, J. SALAS, R. y SOBERÓN, J. La migración internacional de retorno en el Estado de México: oportunidades y retos. Gaceta Laboral, Vol. 17, n. 2, pp.143-168, 2011.

MORENO, G. y ÁlVAREZ, J. Evidencias empíricas sobre el retorno migratorio España-Ecuador. ¿Discurso, mito o realidad? Papeles de Población, Vol. 27, no. 91, 2017.

ORREGO, C. y MARTÍNEZ, J. Retorno en la migración: una mirada a 
sus múltiples facetas. En: LOZANO, F. y MARTÍNEZ, J. (Eds.). Retorno en los procesos migratorios de América Latina. Conceptos, debates, evidencias. Uruguay, TRILCE, 2015.

PADILLA, J. y JARDÓN, A. Migración y empleo: reinserción de los migrantes de retorno al mercado laboral nacional, Instituto de Estudios y Divulgación sobre Migración, México, 2015.

RIVERA, L. ¿Quiénes son los retornados? Apuntes sobre el migrante retornado en el México contemporáneo. En Feldman, B. et al. (Ed.), La construcción social del sujeto migrante en América Latina. Prácticas, representaciones y categorías, CLACSO, 2011.

RIVERA, L. Narrativas de retorno y movilidad. Entre prácticas de involucramiento y espacialidades múltiples en la ciudad. Estudios Políticos, n'. 47, pp.243-264, 2015.

ROJAS, T. La crisis del sector rural y el coste migratorio en México. Revista de Ciencias Sociales de la Universidad Iberoamericana. Año IV, $\mathrm{n}^{\mathrm{o}}$. 8, pp.40-81, 2009.

ROMO, P. et al. Prevalencia de desesperanza y factores sociodemográficos de migrantes mexicanos repatriados. Enfermería Universitaria, Vol. 15, n'.1, pp. 55-62, 2018.

RUVALCABA, J. Estado y violencia en el medio rural de México y Brasil. Desacatos, n'. 14, 2004.

SECRETARIA DE GOBERNACIÓN. Lineamientos de operación del Fondo de Apoyo a Migrantes. Diario Oficial de la Federación, 2016. In: http://www.dof.gob.mx/nota_detalle. php?codigo $=5451774 \&$ fecha $=07 / 09 / 2016$ accedido el 12 feb. 2018.

SECRETARIA DE GOBERNACIÓN. Lineamientos de operación del Fondo de Apoyo a Migrantes. Diario Oficial de la Federación, 2017. In: http://www.dof.gob.mx/nota_detalle. php?codigo $=5478187 \&$ fecha $=31 / 03 / 2017$ accedido el 12 feb. 2018.

UNIDAD DE POLÍTICA MIGRATORIA. Repatriación de mexicanos, Secretaría de Gobernación, 2017. In: http://www.politicamigratoria. gob.mx/es_mx/SEGOB/V_Repatriacion_de_mexicanos_de_EUA accedido el 8 de ene. 2018.

VELASCO, L. Y COUBÈS, M. Reporte sobre dimensión, caracterización y áreas de atención a mexicanos deportados desde Estados Unidos, El Colegio de la Frontera Norte, 2013. In: http://imumi.org/uf/recursos/ reporte-dimension-atecion-mexicanos-deportados.pdf accedido el 10 de sep. 2018. 